\title{
Research Paper: The Efficacy of Operational First Aid Training Course in Preschool Children
}

\author{
Ali Mohajervatan' ${ }^{1}$ (D, Ahmad Reza Raeisi ${ }^{2 *}$, Golrokh Atighechian², Nahid Tavakoli ${ }^{2}$ Hossein Muosavi $^{1}$ (i) \\ 1. Department of Disaster and Emergency Health, School of Management and Medical Information Sciences, Isfahan University of Medical Sciences, \\ Isfahan, Iran. \\ 2. Health Management and Economics Research Center, Isfahan University of Medical Sciences, Isfahan, Iran.
}

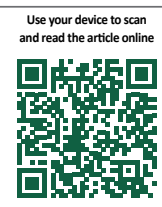

Citation: Mohajervatan A, Raeisi AR, Atighechian G, Tavakoli N, Muosavi H. The Efficacy of Operational First Aid Training Course in Preschool Children. Health in Emergencies and Disasters Quarterly. 2020; 6(1):17-22. http://dx.doi.org/10.32598/hdq.6.1.149.2

doif : http://dx.doi.org/10.32598/hdq.6.1.149.2

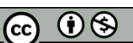

Article info:

Received: 20 Apr 2020

Accepted: 13 Sep 2020

Available Online: 01 Oct 2020

Keywords:

First aid, Preschool children, Training

\section{A B STRACT}

Background: All parents know that keeping their child at home is already difficult, but when the child goes to school, new challenges and hazardous situations will emerge. Preparing children for such situations is one of the tasks of the education system. This study investigated the efficacy of operational first aid training courses in preschool children.

Materials and Methods: This study is a single-group experience. The sample size included 150 children randomly selected from preschools in Isfahan Province, Iran, in spring 2019. They underwent a course of first aid training, and the results were evaluated 3 weeks after training. The SPSS V. 16 was used for data analysis. All tests were conducted at the significance level of 0.05 . Results with $\mathrm{P}<0.05$ will be considered statistically significant.

Results: Quantitative improvements were observed in the children's efficacy in giving first aid. For example, the assessment of consciousness status increased from $51.3 \%$ before training to $64 \%$ after training, or nasal bleeding control increased from $34 \%$ before training to $89.3 \%$ after training.

Conclusion: First aid training courses help children get immediate and adequate help in emergencies. The children can learn the fundamental aspects of first aid, and these skills increase self-care in children. So the first aid teaching program motivates children to perform first aid and develop their helping aptitude.

\section{Introduction}

he evolving conditions of society have made the social life of children more com-

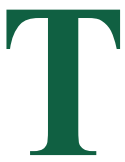
plex [1]. It is estimated that $30 \%$ of children and adolescents encounter high-risk behaviors [2]. They are prone to accidents and poisoning, and these accidents increase as they progress and learn [3]. From 1940 onwards, injuries and accidents account for the largest mortality cause among one year or older children $[4,5]$. Children belong to vulnerable groups [6]. They are more prone to injuries and accidents, especially at school, because they are not mentally and physically mature [7]. They are at greater risk of accidents and injuries because of the involvement in plays and other extracurricular activities [8]. There-

* Corresponding Author:

Ahmad Reza Raeisi, PhD.

Address: Health Management and Economics Research Center, Isfahan University of Medical Sciences, Isfahan, Iran

E-mail: raeisi@mng.mui.ac.ir 
fore, the child's developmental stages require care. Each stage of development is related to the previous stage. Failing to provide proper health care delay growth and development and gradually make it challenging to compensate [6]. Children during their early stages of development and learning process will learn all the new things very fast. So if they receive targeted messages from their parents and relatives, they will never ignore them and accept them [3].

In this context, one of the essential skills that can maintain and enhance their growth and prosperity is problemsolving abilities to meet the changing conditions of life [1]. One way to help children in this way is education. Training in preparing children to deal with new situations [6]. Children need to be educated at all stages of their growth to raise their awareness because education is one of the critical components of understanding their outside [1]. One of the skills that should be considered as the mainstream of health education for all people, especially children, is primary education for lifesaving. The trained people are essential in maintaining their lives and others in emergencies $[9,10]$. A child and adolescent can learn and use first aid training as the only person in emergencies. Therefore, training first aid should be practically and rigorously started for this age group $[11,12]$. Several studies in developed countries show that children can learn first aid skills through education and raise their knowledge and practice in necessary lifesaving conditions [10, 13, 14]. For example, Cardiopulmonary Resuscitation (CPR) is mandatory for school children in the United States, according to the American Heart Association $[15,16]$.

In 2015, the World Health Organization approved cardiopulmonary resuscitation training for school children [17]. De Buck et al. considered first aid training to be broader than CPR training [18]. In Norwegian schools, first aid has been taught in schools since 1961 and is part of the current school curriculum for primary and lower secondary schools [19]. First aid is the provision of limited care for an illness or injury, which may usually be provided by a trained person to a sick or injured patient until definitive medical treatment, or until illness or injury is treated [20]. However, effective lifesaving first aid requires hands-on training by experts, especially where it relates to potentially fatal illnesses and injuries, such as those requiring $\mathrm{CPR}$, as the procedure may be invasive and brings a risk of further damage to the patient [21]. Therefore, it is necessary to take basic measures in this regard, because children are vulnerable and constantly at risk, and in the first minutes after a serious injury, there is an opportunity to eliminate life-threatening. Helping the patient to breathe or control external bleeding increases the likelihood of his or her survival. This study was designed to investigate the effect of first aid education on the relief performance of preschool children in Isfahan Province, Iran in 2019. The results of this study are available to relevant authorities to adopt practical solutions.

\section{Materials and Methods}

This study is a single-group experience. We recruited participants from preschool in Isfahan Province, Iran, in spring 2019. According to the study of Bollig et al. [13] and considering the correct performance rate of $60 \%$ and $8 \%$ error, 150 samples are required. The samples are randomly selected from kindergartens and preschools. The inclusion criterion was 5-7 years old children. Training interventions consisted of ten sessions (45 min for each) for 5 consecutive weeks and 2 sessions per week with the transfer of theoretical knowledge and scenario-based practical first aid skills. The workshop included various aspects of first aid interventions such as painting, playing, and child participation in exercises.

The training was provided by experienced nurses on how to deal with the accident scene and knowing emergency phone numbers, airway management, assessment of the condition of consciousness, victim position recovery, control of nose bleeding, and control of hands or feet bleeding. Data collection will be done through a checklist pre- and post-training. This checklist contains 10 questions. The questions have the same weight and score. The child must determine the correct intervention on each of the visual options. Besides, a practical test was designed to accurately assess their performance by measuring the performance of each child in a scenario for each intervention through observation. The data obtained were described in terms of relative frequency and percentage and presented in tables. The demographic characteristics were reported as mean and standard deviation. The analysis of the data was carried out by comparing the results before and 3 weeks after training. The SPSS 16 was used for the analysis. All tests were conducted at a significance level of 0.05 . The results with $P$ values $<0.05$ will be considered statistically significant.

\section{Results}

The children were 5-7 years old; 76 (50.7\%) were girls and 74 (49.3\%) boys. A comparison was made between the correct performance undertaken by the children before and three weeks after training (Table 1). This Table shows the frequency of actions taken by children in an accident scenario. These actions included requesting for help, knowing emergency phone numbers, assess- 
Table 1. The result of performance of the children before and 3 weeks after training

\begin{tabular}{|c|c|c|c|c|}
\hline \multirow{2}{*}{ Interventions } & \multirow{2}{*}{ Result } & \multicolumn{2}{|c|}{ No. (\%) } & \multirow{2}{*}{$\mathbf{P}$} \\
\hline & & Before Training & After Training & \\
\hline \multirow[b]{2}{*}{ Knowing emergency numbers and call for ambulance } & Correct & $131(87.3)$ & $144(96)$ & \multirow[b]{2}{*}{0.01} \\
\hline & Incorrect & 19 (12.7) & $6(4)$ & \\
\hline \multirow{2}{*}{ Assessment of the condition of consciousness } & Correct & $77(51.3)$ & $96(64)$ & \multirow[b]{2}{*}{0.02} \\
\hline & Incorrect & $73(48.7)$ & $54(36)$ & \\
\hline \multirow[b]{2}{*}{ Correct assessment of the respiratory status } & Correct & $69(46)$ & $131(87)$ & \multirow[b]{2}{*}{0.00} \\
\hline & Incorrect & $81(54)$ & 19 (12.7) & \\
\hline \multirow[b]{2}{*}{ Airways management } & Correct & 53 (35.6) & $127(85.2)$ & \multirow[b]{2}{*}{0.00} \\
\hline & Incorrect & $96(64.4)$ & $23(14.8)$ & \\
\hline \multirow[b]{2}{*}{ Taking a patients recovery position } & Correct & $21(14)$ & $107(71.3)$ & \multirow[b]{2}{*}{0.00} \\
\hline & Incorrect & $129(86)$ & $43(28.7)$ & \\
\hline \multirow{3}{*}{ Avoid airway obstruction } & Correct & $72(48)$ & $137(91.3)$ & \multirow{3}{*}{0.00} \\
\hline & & & & \\
\hline & Incorrect & $78(52)$ & $13(8.7)$ & \\
\hline \multirow{3}{*}{ Control of nose bleeding } & Correct & $51(34)$ & $134(89.3)$ & \multirow{3}{*}{0.00} \\
\hline & & & & \\
\hline & Incorrect & $99(66)$ & $16(10.7)$ & \\
\hline \multirow[b]{2}{*}{ Control of bleeding of hands or feet } & Correct & $98(65.3)$ & $133(88.7)$ & \multirow[b]{2}{*}{0.00} \\
\hline & Incorrect & $52(34.7)$ & $17(11.3)$ & \\
\hline \multirow{2}{*}{$\begin{array}{l}\text { Report to the emergency department about damaged } \\
\text { body organs(identification of body parts) }\end{array}$} & Correct & $150(100)$ & $150(100)$ & \multirow{2}{*}{1} \\
\hline & Incorrect & 0 & 0 & \\
\hline
\end{tabular}

ment of the condition of consciousness, correct assessment of respiratory status, airway's management, taking a patient's recovery position, avoid airway obstruction, control of nose bleeding, control of bleeding of hands or feet, report to the emergency department about damaged body organs (identification of body parts) concerning the three preceding stages.

Requesting for help and assisting victims significantly increased three weeks after training when compared with the pre-training period. The results of this study showed that children's performance in the assessment of the condition of consciousness increased from $51.3 \%$ to $64 \%$, assessment of respiratory status from $46 \%$ to $87 \%$, airway's management from $35.6 \%$ to $85.2 \%$, and controlling limb hemorrhage from $65.3 \%$ to $88.7 \%$. Our study also showed that awareness of emergency numbers and body parts as part of children's educational topics in pre- school. So more than $90 \%$ of children were aware of it before education $(\mathrm{P}<0.05)$.

\section{Discussion}

This study showed that the efficacy of the participants assisting victims in the accident scenario was improved both in quantity and quality after training. This result indicates that children younger than 7 years can learn necessary first aid measures, including calling the ambulance service, handling an unconscious patient, and managing severe bleeding [16]. Other studies also emphasize that children and adolescents between the ages of 5 and 18 can learn some first aid techniques [18, 22]. The results of our study showed that children's performance in the assessment of the condition of consciousness increased from $51.3 \%$ to $64 \%$, assessment of respiratory status from $46 \%$ to $87 \%$, airway's management 
from $35.6 \%$ to $85.2 \%$, controlling limb hemorrhage from $65.3 \%$ to $88.7 \%$. These findings are consistent with the results of the Bollig study, when $70 \%$ of the children assessed consciousness correctly and knew the correct emergency telephone number. Also, $60 \%$ showed a correct breathing assessment, and $40 \%$ of the participants accomplished the other tasks (giving correct emergency call information, knowledge of correct recovery position, correct airway management) correctly [10]. Also, the research by Bánfai showed the same results [23]. In our study, knowing emergency numbers and call for ambulance increase from $87.3 \%$ to $96 \%$. This finding is consistent with the results of the Balint study. According to this study, call the ambulance before training, immediately after training, and 4 months after training were 285 (49\%), 530 (91\%), and 512 (88\%), respectively [16]. We observed an increasing application of the airway management of $35.6 \%$ before training to $85.2 \%$ at 3 weeks after training. However, the improvement of the quality of this management was not remarkable.

Furthermore, our study indicated that the first aid skills learned by the children were reinforced and improved over time. This result is consistent with other studies. It shows that the skills were significantly better than before training in all age groups [24]. Thus it is necessary to plan regular training courses for the children to improve their responsibility and knowledge. First aid training courses help children offer quick and adequate assistance and other emergencies, thus decreasing secondary complications caused by trauma. On the other hand, the school is ideal for teaching first aid skills because the number of trained adults will increase in later generations [25]. First aid is a cost-effective health intervention, so funding should be made available for schools to carry this out (supporting mandatory first aid training in primary schools).

\section{Study limitations}

Our study might not be representative of the whole population of primary school children in Isfahan. Children were re-tested after 3 weeks of training, but we do not know the longer-lasting training effects. A follow-up study in the future could help measure long-term knowledge and skill retention. The actual reaction of these children in a possible real emergency remains unknown. Despite these limitations, the results from our study are promising. Another limitation of the present study is the lack of long-term follow-up of the participants. Further long-term studies are needed to determine the golden time interval for re-training courses.

\section{Conclusion}

Many people require medical aid in emergencies, and the injured may die because first aid is not performed. The main reason for ignoring first aid is the misconception that trying to help in such situations may be a mistake. To change this attitude, education must begin at an early age. Accordingly, beginning first aid education in the first grade of primary school ( 7 years of age and younger) should be mandatory. These children can learn the fundamental aspects of first aid. The first aid teaching program should include the transfer of knowledge and motivate children to perform first aid and develop their helping aptitude.

\section{Ethical Considerations}

\section{Compliance with ethical guidelines}

This study ethically was approved by Health Management and Economics Research Center, Isfahan University of Medical Sciences, Isfahan, Iran. (Research Ethics Code IR.MUI.REC.1397.2.082).

\section{Funding}

This research receives financial support from the Health Management and Economics Research Center, Isfahan University of Medical Sciences, Isfahan (ID: 297082).

\section{Authors' contributions}

Conceptualization and supervision: Ali Mohajervatan, Ahmad Reza Raeisi, and Golrokh Atighechian; Methodology: Golrokh Atighechian; Writing - original draft, and writing - review \& editing: All authors; Data collection: Ali Mohajervatan, Hossein Muosavi; Data analysis: Nahid Tavakoli and Golrokh Atighechian; Funding acquisition and resources: Ahmad Reza Raeisi.

\section{Conflict of interest}

The authors declared no conflict of interest.

\section{Acknowledgments}

The authors would linke to thank the Department of Social Welfare Isfahan Province, who supported this study. Also We thank the School of Nursing and Midwifery, Isfahan University of Medical Sciences, for their contribution to teaching children. 


\section{Refrences}

[1] Vahedi S, Fathiazar E. The effect of social competence training on decreasing in aggression pre-school boys. Journal of Fundamentals of Mental Health. 2006; 8(32):131-40. [DOI: 10.22038/JFMH.2006.1811]

[2] Dryfoos JG. The prevalence of problem behaviors: Implications for programs. In: Weissberg RP, Gullotta TP, Hampton RL, Ryan BA, Adams GR, editors. Healthy children 2010: Enhancing children's wellness. Thousand Oaks: Sage Publications, Inc.; 1997. https://psycnet.apa.org/record/1997-09089-001

[3] Muneeswari B. A study to assess the effectiveness of planned health teaching programme using child-to-child approach on knowledge of selected first aid measures among school children in selected schools at Dharapuram in Tamil Nadu, India. Global Journal of Medicine \& Public Health. 2014; 3(1):18.

[4] Hambidge SJ, Davidson AJ, Gonzales R, Steiner JF. Epidemiology of pediatric injury-related primary care office visits in the United States. Pediatrics. 2002; 109(4):559-65. [DOI:10.1542/peds.109.4.559] [PMID]

[5] Dancho KA, Thompson RH, Rhoades MM. Teaching preschool children to avoid poison hazards. Journal of Applied Behavior Analysis. 2008; 41(2):267-71. [DOI:10.1901/ jaba.2008.41-267] [PMID] [PMCID]

[6] Sharifnia H, Hojati H, Sharifnia M. [The role of pre primary school education on health awareness of first grade students (Persian)]. Nursing And Midwifery Journal. 2011; 9(2). http://unmf.umsu.ac.ir/article-1-307-en.pdf

[7] Pandey R, Chauhan R, Dobhal S, Dabral S, Nathani S, Negi $\mathrm{S}$, et al. First aid knowledge among health assigned teachers of primary schools. International Journal of Research in Medical Sciences. 2017; 5(4):1522-7. [DOI:10.18203/2320-6012. ijrms20171257]

[8] Qureshi FM, Khalid N, Nigah-e-Mumtaz S, Assad T, Noreen K. First aid facilities in the school settings: Are schools able to manage adequately? Pakistan Journal of Medical Sciences. 2018; 34(2):272. [DOI:10.12669/pjms.342.14766] [PMID] [PMCID]

[9] Eisenburger P, Safar P. Life supporting first aid training of the public-review and recommendations. Resuscitation. 1999; 41(1):3-18. [DOI:10.1016/S0300-9572(99)00034-9]

[10] Bollig G, Myklebust AG, Østringen K. Effects of first aid training in the kindergarten-a pilot study. Scandinavian Journal of Trauma, Resuscitation and Emergency Medicine. 2011; 19(1):1-7.[DOI:10.1186/1757-7241-19-13] [PMID] [PMCID]

[11] Uray T, Lunzer A, Ochsenhofer A, Thanikkel L, Zingerle R, Lillie $\mathrm{P}$, et al. Feasibility of Life-Supporting First-Aid (LSFA) training as a mandatory subject in primary schools. Resuscitation. 2003; 59(2):211-20. [DOI:10.1016/S0300-9572(03)00233-8]

[12] Burghofer K, Schlechtriemen T, Lackner C. Konsequenzen aus der Altruismusforschung für die Ausbildung in Erster Hilfe. Notfall+ Rettungsmedizin. 2005; 8(6):408-11. [DOI:10.1007/s10049-005-0762-2]

[13] Bollig G, Wahl HA, Svendsen MV. Primary school children are able to perform basic lifesaving first aid measures. Resuscitation. 2009; 80(6):689-92. [DOI:10.1016/j.resuscitation.2009.03.012] [PMID]
[14] Fleischhackl R, Nuernberger A, Sterz F, Schoenberg C, Urso $\mathrm{T}$, Habart T, et al. School children sufficiently apply life supporting first aid: A prospective investigation. Critical Care. 2009; 13(4):R127. [DOI:10.1186/cc7984] [PMID] [PMCID]

[15] Cave DM, Aufderheide TP, Beeson J, Ellison A, Gregory A, Hazinski MF, et al. Importance and implementation of training in cardiopulmonary resuscitation and automated external defibrillation in schools: A science advisory from the American Heart Association. Circulation. 2011; 123(6):691-706. [DOI:10.1161/CIR.0b013e31820b5328] [PMID]

[16] Bánfai B, Pek E, Pandur A, Csonka H, Betlehem J. 'The year of first aid': Effectiveness of a 3-day first aid programme for 7-14-year-old primary school children. Emergency Medicine Journal. 2017; 34(8):526-32. [DOI:10.1136/ emermed-2016-206284] [PMID] [PMCID]

[17] Böttiger BW, Van Aken H. Kids save lives-: Training school children in cardiopulmonary resuscitation worldwide is now endorsed by the World Health Organization (WHO). Resuscitation. 2015; 94:A5-A7. [DOI:10.1016/j.resuscitation.2015.07.005] [PMID]

[18] De Buck E, Van Remoortel H, Dieltjens T, Verstraeten $\mathrm{H}$, Clarysse M, Moens O, et al. Evidence-based educational pathway for the integration of first aid training in school curricula. Resuscitation. 2015; 94:8-22. [DOI:10.1016/j.resuscitation.2015.06.008] [PMID]

[19] Bakke HK, Bakke HK, Schwebs R. First-aid training in school: Amount, content and hindrances. Acta Anaesthesiologica Scandinavica. 2017; 61(10):1361-70. [DOI:10.1111/ aas.12958] [PMID] [PMCID]

[20] Mobarak AS, Afifi RM, Qulali A. First aid knowledge and attitude of secondary school students in Saudi Arabia. Health 2015; 7(10):1366. [DOI:10.4236/health.2015.710151]

[21] Davies CS, Colquhoun M, Graham S, Evans T, Chamberlain D. Defibrillators in public places: the introduction of a national scheme for public access defibrillation in England. Resuscitation. 2002; 52(1):13-21. [DOI:10.1016/S03009572(01)00439-7]

[22] Wilks J, Pendergast D. Skills for life: First aid and cardiopulmonary resuscitation in schools. Health Education Journal. 2017; 76(8):1009-23. [DOI:10.1177/0017896917728096]

[23] Bánfai B, Pandur A, Schiszler B, Pék E, Radnai B, Bánfai-Csonka $\mathrm{H}$, et al. Little lifesavers: Can we start first aid education in kindergarten? A longitudinal cohort study. Health Education Journal. 2018; 77(8):1007-17. [DOI:10.1177/0017896918786017]

[24] Bandyopadhyay L, Manjula M, Paul B, Dasgupta A. Effectiveness of first-aid training on school students in Singur Block of Hooghly District, West Bengal. Journal of Family Medicine and Primary Care. 2017; 6(1):39-42. [DOI:10.4103/2249 4863.214960] [PMID] [PMCID]

[25] Roppolo LP, Pepe PE. Retention, retention, retention: Targeting the young in CPR skills training! Critical Care. 2009; 13(5):185. [DOI:10.1186/cc7997] [PMID] [PMCID] 
This Page Intentionally Left Blank 